\title{
Influences of Organic Loading, Feed-To-Inoculum Ratio, And Different Pretreatment Strategies On The Methane Production Performance of Eggplant Stalk
}

\section{Zhe Zhu}

Beijing University of Chemical Technology

\section{Si Zhang}

Beijing University of Chemical Technology

Chao Song

Beijing University of Chemical Technology

Ligong Wang

Beijing University of Chemical Technology

\section{Fanfan Cai}

Beijing University of Chemical Technology

Chang Chen ( $\nabla$ chenchang@mail.buct.edu.cn )

Beijing University of Chemical Technology https://orcid.org/0000-0002-0093-3121

Guangqing Liu

Beijing University of Chemical Technology

\section{Research Article}

Keywords: Eggplant stalk, Anaerobic digestion, Methane yield, Response surface methodology,

Pretreatment

Posted Date: October 18th, 2021

DOI: https://doi.org/10.21203/rs.3.rs-983813/v1

License: (c) (1) This work is licensed under a Creative Commons Attribution 4.0 International License.

Read Full License 
4 Biomass Energy and Environmental Engineering Research Center, College of Chemical Engineering,

5 Beijing University of Chemical Technology, Beijing 100029, China

6

$7 \quad$ Corresponding authors

8 Chang Chen's e-mail: chenchang@mail.buct.edu.cn

9 Guangqing Liu's e-mail: gqliu@mail.buct.edu.cn

10 Phone and Fax: +86-10-6444-2375

11 Address: 505 Zonghe Building, 15 North 3rd Ring East Road, Beijing 100029, China

$12 \quad{ }^{1}$ Zhe Zhu and ${ }^{1}$ Si Zhang have contributed equally to this work.

14 Acknowledgements

$15 \quad$ Not applicable. 
Ethics approval and consent to participate

$31 \quad$ Not applicable.

32 Consent for publication

$33 \quad$ Not applicable.

\section{$34 \quad$ Availability of data and materials} supplementary information files.

\section{$37 \quad$ Competing interests}

38 The authors declare that they have no competing interests.

\section{$39 \quad$ Funding}

40 This research did not receive any specific grant from funding agencies in the public, commercial, or not-

41 for-profit sectors.

42 Authors' contributions

$43 \mathrm{ZZ}$ and SZ performed experiment and calculation, wrote the original draft and revised the manuscript;

44 CS, LW and FC helped revise the manuscript; CC and GL provided ideas and resources for the experiment, 45 supervised the experiment process and helped revise the manuscript. All authors read and approved the 46 final manuscript.

47 Acknowledgements

$48 \quad$ Not applicable. 
0

\section{Abstract}

A large amount of eggplant straw (ES) is incinerated after harvesting of eggplant every year, which aggravates environmental pollution and waste of resources. Converting ES into methane through anaerobic digestion (AD) technology may be a potential treatment method, considering the low environmental impact and high energy recovery. Firstly, this study explored the effects of organic loading (OL) and feed to inoculum ratio (F/I ratio) on the $\mathrm{AD}$ of ES by response surface methodology (RSM). In order to achieve higher $\mathrm{AD}$ efficiency, various pretreatments (acid, alkali, alkaline hydrogen peroxide (AHP), microwave and ultrasound) were introduced and comprehensively assessed with regard to methane production performance, organic matter destruction and kinetic parameters. Results showed that OL had a more significant impact on AD process compared to $\mathrm{F} / \mathrm{I}$ ratio and methane production was enhanced remarkably when the OL and $\mathrm{F} / \mathrm{I}$ ratio were $35.0 \mathrm{~g} \mathrm{VS} / \mathrm{L}$ and 3.0, respectively. XRD, FTIR, and SEM analyses of pretreated ES showed that alkali and AHP pretreatments performed better in delignification. Under optimal conditions, the ES pretreated with $1.5 \%$ AHP (adjusted by $\mathrm{KOH}$ ) performed the maximum methane production of $262.2 \mathrm{~mL} / \mathrm{g}$ VS with a $B_{\mathrm{d}}$ of $95.0 \%$, which increased by $334.1 \%$ than untreated ES. This paper not only provides the theoretical data about methane production performance of ES but also gives practical guidance for efficient utilization of similar vegetable straw biowastes, which is also promising for large-scale industrial applications in the future.

Keywords: Eggplant stalk, Anaerobic digestion, Methane yield, Response surface methodology, Pretreatment

5

6

7

8

9




\section{Introduction}

Eggplant is one of the most popular vegetables mainly planted in Asia, with an production volume of approximately 48.28 million metric tons (MTS) in 2019 (Tridge 2019). As an inedible fraction, about 14.48 million MTS of eggplant straw (ES) is discarded after harvesting of eggplant (Ravi et al. 2018; Cai et al. 2019). Because of its organic content, poor management of ES not only causes waste of biomass resources but also poses serious environmental risks. Currently, a considerable amount of ES is combusted in the open field (Sharma et al. 2019), which causes serious air pollution, accelerates the earth's greenhouse effect and conflicts with the concept of green development. This calls for the development of an efficient way to utilize ES to reduce the environmental pollution and resource waste.

Anaerobic digestion (AD) technology is regarded as a highly economical-effective solution that can balance energy recovery and environmental impact, and already has a wide application in the stabilization of biomass wastes with abundant organic matters like carbohydrates (Zhang et al. 2020; Amin et al. 2021). As an organic waste with high carbon content, ES is likely to be a suitable feedstock for AD. Furthermore, the methane yield of lignocellulosic biowaste is deeply influenced by several parameters, in which OL and F/I ratio are recognized as important operational parameters (Mamun and Torii 2017; Sun et al. 2017). Enhancing OL can achieve higher volumetric methane productivity, but extremely high OL may exceed the processing capacity of anaerobic system, leading to the accumulation of volatile fatty acids (VFAs) and VFAs inhibition (Tanimu et al. 2014; Zhang et al. 2019). F/I is closely associated with biodegradability, and higher feedstock concentration decreases its biodegradability, resulting in lower AD efficiency (Kawai et al. 2014). It can be seen that the two parameters of OL and F/I ratio are crucial to obtain satisfactory methane production and stable $\mathrm{AD}$ performance throughout the $\mathrm{AD}$ process. However, no relative literatures have systematically reported the utilizing ES for AD up to now. Hence, it is necessary to explore the responses of AD of ES with different $\mathrm{OL}$ and $\mathrm{F} / \mathrm{I}$ ratio.

In addition, as a lignocellulosic substrate mainly consisting of cellulose, hemicellulose and lignin, ES also faces challenges in methane production. The protective barrier of lignin for the lignocellulose restricts hydrolysis rate of cellulose and hemicellulose, thus limiting the AD efficiency of vegetable straw biomass (Monlau et al. 2013; Phitsuwan et al. 2013; Gu et al. 2020; Song et al. 2021). In recent years, pretreatment (including chemical, physical and biological methods) has achieved increasing great attention in AD process 
112 because it can break down complex and compact structure of lignocellulose and increase the methane 113 production potential of lignocellulosic biomass (Paudel et al. 2017; Wang et al. 2021). Among all the

114 pretreatment strategies, chemical and physical pretreatments are the most common and intensive methods

115 due to their simplicity and effectiveness, which mainly includes acid $\left(\mathrm{H}_{2} \mathrm{SO}_{4}, \mathrm{HCl}, \mathrm{H}_{3} \mathrm{PO}_{4}\right.$, etc.), alkali (e.g.

$116 \mathrm{NaOH}, \mathrm{KOH}, \mathrm{Ca}(\mathrm{OH})_{2}$, etc.), alkaline hydrogen peroxide (AHP), microwave, ultrasound strategies and so

117 on. Considering the recalcitrant nature of vegetable straw biomass, proper pretreatment strategies might be

118 helpful to further improve the utilization efficiency and methane yield of ES. Up to now, no relative

119 researches have been performed to explore the effects of varies pretreatments on ES for AD, and the

120 evaluation of different pretreatments is important for the large-scale utilization of ES for methane production 121 in future.

122 This research set up to (1) explore the methane production performance of ES, (2) identify the effects 123 of different $\mathrm{OL}$ and $\mathrm{F} / \mathrm{I}$ on the $\mathrm{AD}$ of ES by RSM, and (3) investigate an effective pretreatment strategy to 124 maximize AD efficiency of ES.

125 2. Materials and methods

\subsection{Materials}

ES was obtained from a farm in Anhui, China and milled to a particle size of $10 \mathrm{~mm}$ by a high-speed muller (Xingshilihe, Beijing, China), and then carefully reserved at $25^{\circ} \mathrm{C}$ for subsequent use. The inoculum was kindly acquired from a methane plant in Beijing and remove the background methane at $25^{\circ} \mathrm{C}$ for 14 days.

\subsection{Theoretical maximum methane yield and biodegradability}

The theoretical maximum methane potential (MMP) was computed by Eqs. (1) and (2) (Ji et al. 2017; Allison and Simmons 2018). The biodegradability $\left(B_{\mathrm{d}}\right)$ was calculated from Eq. (3), where EMY is the experimental methane yield.

$$
C_{n} H_{a} O_{b} N_{c}+\left(n-\frac{a}{4}-\frac{b}{2}+\frac{3 c}{4}\right) H_{2} O \rightarrow\left(\frac{n}{2}+\frac{a}{8}-\frac{b}{4}-\frac{3 c}{8}\right) C_{4}+\left(\frac{n}{2}-\frac{a}{8}+\frac{b}{4}+\frac{3 c}{8}\right) C O_{2}+c N H_{4}
$$




$$
\begin{gathered}
M M P(m L / g V S)=\frac{22.4 \times 1000 \times\left(\frac{n}{2}+\frac{a}{8}-\frac{b}{4}-\frac{3 c}{8}\right)}{12 n+a+16 b+14 c} \times(1-\text { lignin } \%) \\
B_{\mathrm{d}}=\frac{E M Y}{M M P} \times 100 \%
\end{gathered}
$$

\subsection{RSM parameters and analysis}

RSM is recognized as a mathematical and statistical method for determining optimal operating parameters and analyzing the influence of an independent factor on the response variable (Feng et al. 2017; Arhin et al. 2018). It already has a wide application in experiment design and process optimization of AD (Song et al. 2012). In this research, the RSM was conducted by central composite design (CCD) and each factor was set at five levels: $0, \pm 1$, and $\pm \alpha$. The $\alpha$ was defined by Eq. (4) (Ahmad et al. 2009) :

$$
\alpha=2^{\frac{k}{4}}
$$

where $k$ represents the number of variables, OL and F/I ratio are separately set in the ranges of 3.0-35.0 g $\mathrm{VS} / \mathrm{L}$ and 0.3-3.0 in terms of previous study (Zhang et al. 2018a). The values of these variables were listed in Table S1 (Supplementary materials) and the values of variables are shown in Table 2. A second-order polynomial function is employed as:

$$
Y=\beta_{0}+\beta_{1} A+\beta_{2} B+\beta_{11} A^{2}+\beta_{22} B^{2}+\beta_{12} A B
$$

where $Y, A$, and $B$ represent EMY, F/I ratio, and OL; $\beta_{0}$ represents a constant; $\beta_{1}, \beta_{2}, \beta_{11}, \beta_{12}$, and $\beta_{22}$ denote the coefficients of the corresponding terms of the polynomial.

\subsection{Pretreatments}

In this study, $\mathrm{H}_{2} \mathrm{SO}_{4}$ and $\mathrm{H}_{3} \mathrm{PO}_{4}, \mathrm{NaOH}, \mathrm{KOH}$ and $\mathrm{Ca}(\mathrm{OH})_{2}$, $\mathrm{AHP}$ (adjusted by $\mathrm{KOH}, \mathrm{NaOH}$ and $\left.\mathrm{Ca}(\mathrm{OH})_{2}\right)$ respectively microwave $(210 \mathrm{~W}, 420 \mathrm{~W}$ and $630 \mathrm{~W})$ and ultrasound $(40 \mathrm{kHz}, 200 \mathrm{~W})$ were introduced for pretreatments of raw ES. The mass concentration of $\mathrm{H}_{2} \mathrm{SO}_{4}, \mathrm{H}_{3} \mathrm{PO}_{4}$ and AHP was set to $1.5 \%$, $3.0 \%, 4.5 \%$ and $6.0 \%$; while $\mathrm{NaOH}, \mathrm{KOH}$ and $\mathrm{Ca}(\mathrm{OH})_{2}$ was $1.0 \%, 2.0 \%, 3.0 \%$ and $4.0 \%$, respectively. The $\mathrm{pH}$ of AHP pretreatment solutions were adjusted to 11.5 by $\mathrm{NaOH}, \mathrm{KOH}$ and $\mathrm{Ca}(\mathrm{OH})_{2}$, respectively. The power of microwave was set to $210 \mathrm{~W}, 420 \mathrm{~W}$, and $630 \mathrm{~W}$, respectively. The diagram of pretreatments setup 
was presented in Table S2. The moisture content (MC) was adjusted by Eq. (6) until $90 \%$ in the pretreated vessel (Zhang et al. 2018b).

$$
\operatorname{MC}(\%)=\left(1-\frac{\text { dry matter weight of ES }}{\text { weight of ES }+ \text { water added }}\right) \times 100 \%
$$

All samples were mixed every $6 \mathrm{~h}$ under room temperature and pretreated for $24 \mathrm{~h}$, and then were kept at $4^{\circ}$

C.

\subsection{Anaerobic digestion}

The AD experiments were conducted in $500 \mathrm{~mL}$ serum vials with $250 \mathrm{~mL}$ of working volume at $37^{\circ} \mathrm{C}$ and each group had two replicates. To create an anaerobic environment, the headspace of reactors was flushed with nitrogen gas for about $2 \mathrm{~min}$ and then these reactors were sealed. The headspace pressure was measured before and after releasing methane to calculate cumulative methane yield (CMY), as shown by Eq. (7) (Rincón et al. 2012):

where $V_{\text {biogae }}$ means the daily methane volume (L), $\Delta P$ refers to the absolute pressure difference (KPa), $V_{\text {head }}$ stands for the volume of the headspace (L), $C$ denotes the molar volume $(22.41 \mathrm{~L} / \mathrm{mol}), R$ indicates the gas constant $(83.14 \mathrm{~L} \mathrm{mbar} /(\mathrm{K} \mathrm{mol}))$, and $T$ is the absolute temperature $(\mathrm{K})$.

\subsection{Analytical methods}

Total solids (TS) and volatile solids (VS) of ES were determined as reported by Zimmerman (Zimmerman et al. 2003). The elemental compositions (C, H, N and S) were measured by an elemental detector (VarioEL cube, Germany) and then the oxygen content was estimated regarding to $\mathrm{C}+\mathrm{H}+\mathrm{O}+\mathrm{N}=$ 99.5\% on the basis of VS (Shen et al. 2018; Rincón et al. 2012).

The lignocellulosic contents in ES were measured by an A2000 fiber analyzer (ANKOM, USA), whose operation procedure was reported elsewhere (Shen et al. 2019). The functional groups and chemical bonds were examined by Fourier transform infrared spectroscopy (FTIR, Nicolet 6700, USA), the morphological characteristics were detected by surface electron microscopy (SEM, Hitachi S-4700, Japan), and the 
184 crystallinity index (CrI) was determined by X-ray diffraction (XRD, Bruker D8-Advance, Germany).

\subsection{Kinetic models}

Three traditional mathematical models (first-order, Cone, and modified Gompertz) have been introduced to fit the CMY curves, as shown by Eqs. (8), (9), and (10), respectively (Siles et al. 2007; Li et al. 2012; Shen et al. 2018; Cai et al. 2019).

$$
B=B_{0}[1-\exp (-k t)]
$$

where $B$ and $B_{0}$ denotes the simulated CMY (mL/g VS) and the simulated maximum CMY (mL/g VS), $k$ is the rate constant (1/d), $t$ means the $\mathrm{AD}$ time (d), $\mu_{M}$ stands for the maximum methane yield rate (mL/g VS/day), $\lambda$ refers to the lag phase time (d), $e$ is a constant ( $e=2.718)$, and $n$ is a dimensionless factor.

\subsection{Statistical analysis}

The OriginPro 2021 Student Edition (Origin lab, Massachusetts, USA) was used for date calculation, modeling, and charting. The accuracy of the models is evaluated by analysis of variance in Excel statistic.

\section{Results and discussion}

\subsection{Features of ES}

The properties of feedstock and inoculum were listed in Table 1. It is apparent from this table that the TS of ES was $91.3 \%$ and the VS/TS ratio reached $93.3 \%$ to $93.8 \%$, indicating the organic matter content of ES is high and suitable for methane production through AD. The cellulose, hemicellulose, and lignin contents of ES were $50.6 \%, 15.1 \%$, and $19.9 \%$, respectively. Moreover, the carbon-to-nitrogen $(\mathrm{C} / \mathrm{N})$ ratio is an important factor for nutrition balance in $\mathrm{AD}$ process, and the $\mathrm{C} / \mathrm{N}$ ration of $\mathrm{ES}$ was 19.1, which is close to the preferred value (20.0-25.0) for $\mathrm{AD}$ (Shen et al. 2019). In summary, these characteristics suggested that $\mathrm{ES}$ could be utilizable as a feedstock for the $\mathrm{AD}$ process. According to its element compositions, the chemical formula of ES was determined to be $\mathrm{C}_{22.7} \mathrm{H}_{36.4} \mathrm{O}_{21.3} \mathrm{~N}$, and its MMP is $275.9 \mathrm{~mL} / \mathrm{g}$ VS. 


\subsection{Impacts of $\mathrm{OL}$ and $\mathrm{F} / \mathrm{I}$ ratio on methane produce performance of $\mathrm{ES}$}

The 3D response surfaces and 2D contour plots simulated by EMY are shown in Figure 1. It could be observed that the EMY had a sharp increase with increasing OL from $3.0 \mathrm{~g} \mathrm{VS} / \mathrm{L}$ to $35.0 \mathrm{~g} \mathrm{VS} / \mathrm{L}$ at a constant $\mathrm{F} / \mathrm{I}$ ratio, while it slowly changed with $\mathrm{F} / \mathrm{I}$ ratio at a constant OL. Consequently, the OL perhaps was a major determinant on methane production during AD of ES and the highest EMY was achieved at the F/I ratio and OL of 3.0 and $35.0 \mathrm{~g} \mathrm{VS/L}$ as shown in Figure 1a.

\subsection{Determination of the suitable $\mathrm{OL}$ and $\mathrm{F} / \mathrm{I}$ ratio for $\mathrm{AD}$ process of $\mathrm{ES}$}

The experiment obtained the second-order polynomial of ES and shown as follows:

$$
Y=40.11-22.88 A+3.19 B+0.62 A B+2.37 A^{2}-0.06 B^{2}
$$

where $Y, A$ and $B$ stand for EMY of ES, F/I ratio and OL, respectively. The results of the significance ANOVA of the RSM for ES are listed in Table S3. Over the whole RSM, the $\mathrm{R}^{2}$ was 0.937 , which exhibited a good fitting degree. Also, the equation had a high F-value of 20.75 and a low p-value of $0.001(<0.05)$, showing the significance of these parameters (Kleingesinds et al. 2018). The actual and predicted EMY were displayed in Table 2 and no obvious difference was observed, which also indicated the accuracy of RSM model. The predicted EMY of ES was $92.8 \mathrm{~mL} / \mathrm{g} \mathrm{VS}$ at an OL of $35 \mathrm{~g} \mathrm{VS} / \mathrm{L}$ and $\mathrm{F} / \mathrm{I}$ ratio of 3.0 corresponding to the validated methane yield of $110.3 \mathrm{~mL} / \mathrm{g} \mathrm{VS}$, further illustrating the credibility of the RSM.

\subsection{Influences of various pretreatments on AD performance of ES}

The CMY of the different pretreated ES is shown in Figure 2. Acid pretreatments showed little improvement of EMY of ES, the highest EMY of $\mathrm{H}_{2} \mathrm{SO}_{4}$ and $\mathrm{H}_{3} \mathrm{PO}_{4}$ pretreated ES were $70.5 \mathrm{~mL} / \mathrm{g}$ VS and $86.2 \mathrm{~mL} / \mathrm{g} \mathrm{VS}$, which were did not significantly differ from that $(60.4 \mathrm{~mL} / \mathrm{g}$ VS) of the untreated ES. The EMY of alkali and AHP pretreated ES improved significantly. It could be found that the highest EMY of alkaline pretreated ES were $202.8 \mathrm{~mL} / \mathrm{g}$ VS in $4.0 \% \mathrm{NaOH}, 159.0 \mathrm{~mL} / \mathrm{g}$ VS in $4.0 \% \mathrm{KOH}$, and $151.7 \mathrm{~mL} / \mathrm{g}$ VS in $2.0 \% \mathrm{Ca}(\mathrm{OH})_{2}$, respectively. For AHP pretreatments, the $6.0 \%$ AHP (adjusted by $\mathrm{NaOH}$ ), $4.5 \%$ AHP (adjusted by $\mathrm{KOH}$ ), and 1.5\% AHP (adjusted by $\mathrm{Ca}(\mathrm{OH})_{2}$ ) pretreatment groups had the maximum EMY of $261.6 \mathrm{~mL} / \mathrm{g} \mathrm{VS}, 251.9 \mathrm{~mL} / \mathrm{g} \mathrm{VS}$, and $124.4 \mathrm{~mL} / \mathrm{g} \mathrm{VS}$, respectively. The microwave and ultrasound pretreatments slightly increased methane yield of ES, and the highest EMY were $75.7 \mathrm{~mL} / \mathrm{g} \mathrm{VS}$ in microwave pretreatment (630 W, $10 \mathrm{~min}$ ) and $80.2 \mathrm{~mL} / \mathrm{g} \mathrm{VS}$ in ultrasonic pretreatment (60 min), respectively. As shown 
in Figure 2k, it is obvious that alkali and AHP pretreatments are better for enhancing methane production potential, and $\mathrm{NaOH}, \mathrm{KOH}$, and $\mathrm{AHP}$ (adjusted by $\mathrm{NaOH}$ and $\mathrm{KOH}$ ) pretreated ES merited to be conducted $\mathrm{AD}$ experiment under optimal OL and $\mathrm{F} / \mathrm{I}$ ratio conditions in order to further improve its methane yield.

The mass concentration of $\mathrm{NaOH}, \mathrm{KOH}$, and $\mathrm{AHP}$ (adjusted by $\mathrm{NaOH}$ and $\mathrm{KOH}$ ) pretreatments was set to $1.5 \%, 3.0 \%, 4.5 \%$ and $6.0 \%$, and experimental pretreatments setup is presented in Table S4. Then pretreated ES by above four methods were subjected to $\mathrm{AD}$ experiments under optimal digestion conditions and the CMY of pretreated ES during AD process were analyzed to determine the best pretreatment method. The methane performance of ES under each pretreatment is illustrated in Table 3 and Figure 3. As shown, the trends of the CMY in the AD process of ES were similar: they increased sharply at first and then slowed down gradually. As for the $\mathrm{NaOH}$ pretreatment, the maximum cumulative methane production was attained at $3 \%$ dose, followed by the ES with a concentration of $1.5 \% \mathrm{NaOH}$ pretreatment. Furthermore, it could be seen that that the improvement in $\mathrm{CMY}$ of $4.5 \%$ and $6 \% \mathrm{NaOH}$ pretreated ES were relatively lower compared to $3 \%$ and $1.5 \% \mathrm{NaOH}$ pretreatments $(\mathrm{P}<0.05)$. There were two possible explanations for this result, much organics was lost in $4.5 \%$ and $6.0 \% \mathrm{KOH}$ solutions, or the high concentration of $\mathrm{NaOH}$ caused excessive hydrolysis rate and the accumulation of VFAs, resulting in VFAs inhibition. For the $\mathrm{KOH}$ pretreatment, the highest cumulative methane production of ES gained at $6 \%$ dose, which was significantly higher than the results at other concentrations of $\mathrm{KOH}$ pretreatment $(\mathrm{P}<0.05)$. As shown in Figure $3 \mathrm{c}$, all pretreatments showed a significantly higher CMY than unpretreated ES and no significant difference can be found in terms of the maximum cumulative methane production of pretreated samples. Considering the economic factor and methane produce performance, $1.5 \%$ was determined to be the optimum concentration in AHP (adjusted by $\mathrm{NaOH}$ ) pretreatment strategy. As shown in Figure 3d, the highest CMY of 1.5\% and 3.0\% AHP pretreated ES were significantly higher than the CMY of $4.5 \%$ and $6.0 \%$ AHP pretreated ES $(\mathrm{P}<0.05)$. While the comparison between 1.5\% AHP and 3.0\% AHP pretreated ES reveal that no significant difference can be found in the highest methane yield. In order to reduce the cost, $1.5 \%$ was selected as the best AHP (adjusted by $\mathrm{NaOH}$ ) dose. Based on the results above, the highest $\mathrm{CMY}$ of $\mathrm{NaOH}, \mathrm{KOH}$, and $\mathrm{AHP}$ (adjusted by $\mathrm{NaOH}$ or $\mathrm{KOH}$ ) pretreatment groups occurred at the concentration of $3.0 \%, 6.0 \%, 1.5 \%$, and $1.5 \%$, respectively, which were $228.1 \mathrm{~mL} / \mathrm{g} \mathrm{VS}, 260.1 \mathrm{~mL} / \mathrm{g} \mathrm{VS}, 251.0 \mathrm{~mL} / \mathrm{g} \mathrm{VS}$ and $262.2 \mathrm{~mL} / \mathrm{g}$ VS with a respective increase of $277.6 \%, 330.6 \%, 315.6 \%$ and $334.1 \%$ than untreated. Therefore, the optimal strategy for AD of ES was 


\subsection{Kinetic analysis}

The first-order, Cone, and modified Gompertz models were applied for simulating the $\mathrm{CMY}$ of $\mathrm{NaOH}$, $\mathrm{KOH}$, and AHP (adjusted by $\mathrm{NaOH}$ or $\mathrm{KOH}$ ) pretreated ES, respectively. All kinetic parameters were estimated and the corresponding results were exhibited in the Table 3. It is apparent from this table that the chosen samples. The all $B_{0}$ values were close to the EMY of all samples, which further confirmed the coefficients of correlation $\left(\mathrm{R}^{2}\right)$ in the first-order, Cone, and modified Gompertz models ranged from 0.955 to 0.987, 0.987 to 0.994 , and 0.969 to 0.989 , which suggested these models were well fitted to the CMY of all reliability of parameters analysis using the three models.

274 However, a low $k$ doesn't indicate a low EMY because the hydrolysis rate alone can't fully determine the 275 methane performance. Further analysis showed that the $B_{0}$ values from the two models were higher than the $276 B_{0}$ of untreated ES obviously, which suggested that all the pretreatment methods are useful for ES to improve 277 its AD efficiency.

278 For the modified Gompertz model, $\lambda$ represents the lag-phase time and a lower $\lambda$ suggests a shorter 279 time to start anaerobic ferment. The $\lambda$ of $3.0 \% \mathrm{NaOH}, 6.0 \% \mathrm{KOH}$ and $1.5 \% \mathrm{AHP}$ (adjusted by $\mathrm{NaOH}$ ) 280 treated ES reduced compared to the untreated ES. However, the $\lambda$ of $1.5 \%$ AHP (adjusted by KOH) treated 281 ES was longer than the untreated ES, which is consistent with the results in Figure 3. In addition, the $\mu_{M}$ 282 corresponds to the EMY rate and the $\mu_{M}$ of all pretreated samples is higher than untreated ES. Especially the $\mu_{M}$ of $1.5 \%$ AHP (adjusted by $\mathrm{KOH}$ ) pretreated ES improved from 2.53 to 10.91, which suggested that the

$284 \quad 1.5 \%$ AHP (adjusted by KOH) pretreatment had the most favorable digestion efficiency.

285

\subsection{Composition changes of ES after different pretreatments}

The characteristics (VS/TS, cellulose, hemicellulose, and lignin) of pretreated ES were measured and shown in Table 4. After pretreatments of $\mathrm{NaOH}, \mathrm{KOH}, \mathrm{AHP}$ (adjusted by $\mathrm{NaOH}$ and $\mathrm{KOH}$ ), the VS/TS ratios corresponded to $59.7 \%, 68.8 \%, 64.9 \%$, and $67.8 \%$ (reduced by $26.4 \%-36.1 \%$ than untreated ES), suggesting that some organic matters were dissolved and more contributable to the degradation of ES. Moreover, it was observed that a decrease in hemicellulose content from from $15.1 \%$ to $7.8-10.5 \%$ after the above-mentioned 
pretreatments. This might be related to that alkali and AHP pretreatments probably broke the ester bond between hemicellulose and lignin, which resulted to the degradation of hemicelluloses (Kaur and Phutela 2016). Furthermore, AHP (adjusted by $\mathrm{NaOH}$ and $\mathrm{KOH}$ ) pretreatments were more effective in delignification, which decreased lignin contents from $19.9 \%$ to $15.6 \%$ and $16.2 \%$. It might be inferred that AHP pretreatments ruin the bond between lignin and partially dissolved hemicellulose by cleavages of hydrogen bond, and thus decreased lignin content (Perendeci et al. 2018). However, the lignocellulose after acid, microwave, and ultrasound pretreatments hardly changed, indicating the limited impact of these pretreatment strategies structure of ES.

\subsection{Structural changes of pretreated ES}

\subsubsection{FTIR analysis}

The structural arrangement of the functional groups existed in untreated and pretreated ES was analyzed by FTIR (Figure S1). The absorbance at $3400 \mathrm{~cm}^{-1}, 2900 \mathrm{~cm}^{-1}, 1439 \mathrm{~cm}^{-1}$ and $1050 \mathrm{~cm}^{-1}$ were responsible for $\mathrm{O}-\mathrm{H}, \mathrm{C}-\mathrm{H}, \mathrm{C}-\mathrm{O}, \mathrm{C}-\mathrm{C}$ bonds in cellulose. There were no significant differences between them, indicating that the cellulose content of ES almost unchanged. The absorbance at $1734 \mathrm{~cm}^{-1}$ is responsible for $\mathrm{C}=\mathrm{O}$ bonds in acetyl and carboxylic acids and $1716 \mathrm{~cm}^{-1}$ is $\mathrm{C}=\mathrm{O}$ or $\mathrm{C}=\mathrm{C}$ bonds in aromatic ring, which were correlated with the lignin structure had flattened or disappeared completely with alkali and AHP pretreatments due to the action of strong oxidation (Yao et al. 2018). At the same time, the reduction of $1720 \mathrm{~cm}^{-1}$ denoting carboxylic acid and $\mathrm{C}=\mathrm{O}$ bond in hemicellulose illustrated the effective hemicellulose removal (Kang et al. 2018). These absorbance bands were greatly reduced, indicating that alkali and AHP pretreatments had a good effect on changing the internal structure of ES.

\subsubsection{SEM analysis}

315 and irregular (Fig. S2D, Fig. S2E, Fig. S2G, and Fig. S2H, respectively). These structural changes can

316 improve the exposure of lignin and cellulose, hence, the negative effect of lignin on AD hydrolysis process

317 was effectively weakened. These results suggested that $\mathrm{NaOH}, \mathrm{KOH}$, and $\mathrm{AHP}$ (adjusted by $\mathrm{NaOH}$ and $\mathrm{KOH}$ )

318 pretreatments were more useful to break down the structure of ES and may be helpful in enhancing AD 
efficiency.

\subsubsection{XRD analysis}

Furthermore, the XRD patterns of ES before and after pretreatment is shown in Figure S3. The three peaks at $16^{\circ}, 22^{\circ}$ and $35^{\circ}$ of ES were similar, which represented the cellulose I and suggested the crystalline structure of cellulose was not changed. Further analysis shows that the CrI of raw ES was $39.25 \%$ and it increased to $48.19 \%, 47.86 \%, 49.13 \%$, and $49.21 \%$ after $\mathrm{NaOH}$, KOH, AHP (adjusted by $\mathrm{NaOH}$ and $\mathrm{KOH}$ ) pretreatment. It could be that most of the non-crystalline components such as lignin and hemicellulose were effectively removed by above pretreatments.

Overall, $\mathrm{NaOH}, \mathrm{KOH}$, and $\mathrm{AHP}$ (adjusted by $\mathrm{NaOH}$ or $\mathrm{KOH}$ ) pretreatments could efficiently minimize the fractions of hemicellulose and lignin that interfered in the hydrolysis process and at the same time increased the cellulosic fraction for AD.

\section{Conclusion}

This study firstly demonstrated that ES as a novel bioenergy feedstock is suitable for methane production via $\mathrm{AD}$, and then assessed the influences of $\mathrm{OL}, \mathrm{F} / \mathrm{I}$ ratio, and different pretreatment strategies on the methane production performance of ES. The results of this study showed that the AD of ES performed best at OL and $\mathrm{F} / \mathrm{I}$ ratio of $35 \mathrm{~g} \mathrm{VS} / \mathrm{L}$ and 3.0. Among all the pretreatment strategies, alkali and AHP pretreatments showed tremendous advantages in breaking down the complicated structure of lignocellulose. Under optimal operating conditions, 1.5\% AHP (adjusted by $\mathrm{KOH}$ ) pretreated ES achieved the maximum EMY of 262.2 $\mathrm{mL} / \mathrm{g}$ VS and biodegradability $\left(B_{d}\right)$ of $95.0 \%$, with an improvement of $334.1 \%$ over the untreated ES. In conclusion, this study describes a suitable route to utilize ES and offers a promising pretreatment strategy to improve its methane production performance, which not only fills in the blank in scientific research but also provides a reference for the full utilization of other vegetable straw waste in an environment friendly way.

\section{References}

Ahmad AL, Low SC, Shukor SRA, Ismail A (2009) Optimization of membrane performance by thermalmechanical stretching process using responses surface methodology (RSM). Sep Purif Technol 66:177-186. https://doi.org/10.1016/j.seppur.2008.11.007

Allison BJ, Simmons CW (2018) Obtaining multiple coproducts from red grape pomace via anthocyanin extraction and biogas production. J Agric Food Chem 66:8045-8053. https://doi.org/10.1021/acs.jafc.8b02250

Amin FR, Khalid H, Li W, et al (2021) Enhanced methane production and energy potential from rice straw 
by employing microaerobic pretreatment via anaerobic digestion. J Clean Prod 296:126434. https://doi.org/10.1016/j.jclepro.2021.126434

Arhin SG, Banadda N, Komakech AJ, et al (2018) Optimization of hybrid coagulation-ultrafiltration process for potable water treatment using response surface methodology. Water Supply 18:862-874. https://doi.org/10.2166/ws.2017.159

Cai F, Yan H, Zhang R, et al (2019) Prediction of methane production performances based on determination of organic components for different vegetable wastes. Int J Agric Biol Eng 12:154-159. https://doi.org/10.25165/j.ijabe.20191203.4705

Feng J, Zhang J, Zhang J, et al (2017) Enhanced methane production of vinegar residue by response surface methodology (RSM). AMB Express 7:89. https://doi.org/10.1186/s13568-017-0392-3

Gu Y, Cai F, Zhu Z, et al (2020) Improving the methane production from zucchini stem by response surface methodology and different pretreatments. Ind Crops Prod 150:112402. https://doi.org/10.1016/j.indcrop.2020.112402

Ji J, Zhang J, Yang L, et al (2017) Impact of co-pretreatment of calcium hydroxide and steam explosion on anaerobic digestion efficiency with corn stover. Environ Technol 38:1465-1473. https://doi.org/10.1080/09593330.2016.1234001

Kang X, Sun Y, Li L, et al (2018) Improving methane production from anaerobic digestion of Pennisetum Hybrid by alkaline pretreatment. Bioresour Technol 255:205-212. https://doi.org/10.1016/j.biortech.2017.12.001

Kaur K, Phutela UG (2016) Enhancement of paddy straw digestibility and biogas production by sodium hydroxide-microwave pretreatment. Renew Energy 92:178-184. https://doi.org/10.1016/j.renene.2016.01.083

Kawai M, Nagao N, Tajima N, et al (2014) The effect of the labile organic fraction in food waste and the substrate/inoculum ratio on anaerobic digestion for a reliable methane yield. Bioresour Technol 157:174-180. https://doi.org/10.1016/j.biortech.2014.01.018

Kleingesinds EK, José ÁHM, Brumano LP, et al (2018) Intensification of bioethanol production by using Tween 80 to enhance dilute acid pretreatment and enzymatic saccharification of corncob. Ind Crops Prod 124:166-176. https://doi.org/10.1016/j.indcrop.2018.07.037

Li L, Kong X, Yang F, et al (2012) Biogas production potential and kinetics of microwave and conventional thermal pretreatment of grass. Appl Biochem Biotechnol 166:1183-1191. https://doi.org/10.1007/s12010-011-9503-9

Mamun MRA, Torii S (2017) Comparison effect of feedstock to inoculum ratios on biogas yields of cafeteria, vegetable, fruit wastes with cattle manure using co-digestion process. Int J Green Energy 14:665673. https://doi.org/10.1080/15435075.2017.1318071

Monlau F, Latrille E, Da Costa AC, et al (2013) Enhancement of methane production from sunflower oil cakes by dilute acid pretreatment. Appl Energy 102:1105-1113. https://doi.org/10.1016/j.apenergy.2012.06.042 
Paudel SR, Banjara SP, Choi OK, et al (2017) Pretreatment of agricultural biomass for anaerobic digestion: Current state and challenges. Bioresour Technol 245:1194-1205. https://doi.org/10.1016/j.biortech.2017.08.182

Perendeci N, Gökgöl S, Orhon D (2018) Impact of alkaline H2O2 pretreatment on methane generation potential of greenhouse crop waste under anaerobic conditions. Molecules 23:1794. https://doi.org/10.3390/molecules23071794

Phitsuwan P, Sakka K, Ratanakhanokchai K (2013) Improvement of lignocellulosic biomass in planta: A review of feedstocks, biomass recalcitrance, and strategic manipulation of ideal plants designed for ethanol production and processability. Biomass Bioenergy 58:390-405. https://doi.org/10.1016/j.biombioe.2013.08.027

Ravi PP, Lindner J, Oechsner H, Lemmer A (2018) Effects of target pH-value on organic acids and methane production in two-stage anaerobic digestion of vegetable waste. Bioresour Technol 247:96-102. https://doi.org/10.1016/j.biortech.2017.09.068

Rincón B, Heaven S, Banks CJ, Zhang Y (2012) Anaerobic digestion of whole-crop winter wheat silage for renewable energy production. Energy Fuels 26:2357-2364. https://doi.org/10.1021/ef201985x

Sharma B, Vaish B, Monika, et al (2019) Recycling of organic wastes in agriculture: An environmental perspective. Int J Environ Res 13:409-429. https://doi.org/10.1007/s41742-019-00175-y

Shen J, Yan H, Zhang R, et al (2018) Characterization and methane production of different nut residue wastes in anaerobic digestion. Renew Energy 116:835-841. https://doi.org/10.1016/j.renene.2017.09.018

Shen J, Zhao C, Liu Y, et al (2019) Biogas production from anaerobic co-digestion of durian shell with chicken, dairy, and pig manures. Energy Convers Manag 198:110535. https://doi.org/10.1016/j.enconman.2018.06.099

Siles JÁ, de los Ángeles Martín M, Martín A, et al (2007) Anaerobic digestion of wastewater derived from the pressing of orange peel generated in orange juice production. J Agric Food Chem 55:1905-1914. https://doi.org/10.1021/jf0630623

Song C, Li W, Cai F, et al (2021) Anaerobic and Microaerobic Pretreatment for Improving Methane Production From Paper Waste in Anaerobic Digestion. Front Microbiol 12:688290. https://doi.org/10.3389/fmicb.2021.688290

Song Z, Yang G, Han X, et al (2012) Optimization of the alkaline pretreatment of rice straw for enhanced methane yield. BioMed Res Int 2013:1-9. https://doi.org/10.1155/2013/968692

Sun M-T, Fan X-L, Zhao X-X, et al (2017) Effects of organic loading rate on biogas production from macroalgae: Performance and microbial community structure. Bioresour Technol 235:292-300. https://doi.org/10.1016/j.biortech.2017.03.075

Tanimu MI, Ghazi TIM, Harun MR, Idris A (2014) Effect of feed loading on biogas methane production in batch mesophilic anaerobic digesters treating food waste. Int J Chem Environ 5:7

Tridge (2019) Overview of Global Eggplant Market. In: Eggplant Suppliers Top Ctries. https://www.tridge.com/intelligences/eggplant. Accessed 13 Sep 2021 
Wang L, Liu C, Wei B, et al (2021) Effects of different microbial pretreatments on the anaerobic digestion of giant grass under anaerobic and microaerobic conditions. Bioresour Technol 337:125456. https://doi.org/10.1016/j.biortech.2021.125456

Yao Y, Bergeron AD, Davaritouchaee M (2018) Methane recovery from anaerobic digestion of ureapretreated wheat straw. Renew Energy 115:139-148. https://doi.org/10.1016/j.renene.2017.08.038

Zhang H, Khalid H, Li W, et al (2018a) Employing response surface methodology (RSM) to improve methane production from cotton stalk. Environ Sci Pollut Res 25:7618-7624. https://doi.org/10.1007/s11356-017-0682-y

Zhang H, Ning Z, Khalid H, et al (2018b) Enhancement of methane production from cotton stalk using different pretreatment techniques. Sci Rep 8:3463. https://doi.org/10.1038/s41598-018-21413-x

Zhang H, Wang L, Dai Z, et al (2020) Effect of organic loading, feed-to-inoculum ratio, and pretreatment on the anaerobic digestion of tobacco stalks. Bioresour Technol 298:122474. https://doi.org/10.1016/j.biortech.2019.122474

Zhang W, Li L, Xing W, et al (2019) Dynamic behaviors of batch anaerobic systems of food waste for methane production under different organic loads, substrate to inoculum ratios and initial $\mathrm{pH}$. $\mathrm{J}$ Biosci Bioeng 128:733-743. https://doi.org/10.1016/j.jbiosc.2019.05.013

Zimmerman RK, Nowalk MP, Raymund M, et al (2003) Tailored interventions to increase influenza vaccination in neighborhood health centers serving the disadvantaged. Am J Public Health 93:16991705. https://doi.org/10.2105/AJPH.93.10.1699

3

44

5

6

7

.

9

0




\section{Tables captions}

458 Table 1 Characterizations of the ES and inoculum

459 Table 2 The values of the coded, actual, and response variables of RSM

460 Table 3 The kinetic parameters of optimal pretreatments

461 Table 4 The Characteristics a of pretreated ES

\section{$462 \quad$ Figures captions}

463 Fig. 1 3D response surfaces (a) and 2D contour plots (b) obtained by RSM.

464 Fig. 2 The CMY of ES, (a) $\mathrm{H}_{2} \mathrm{SO}_{4}$-pretreated ES; (b) $\mathrm{H}_{3} \mathrm{PO}_{4}$-pretreated ES; (c) NaOH-pretreated ES; (d)

$465 \mathrm{KOH}-$ pretreated ES; (e) $\mathrm{Ca}(\mathrm{OH})_{2}$-pretreated ES; (f) AHP-pretreated ES (adjusted by $\mathrm{NaOH}$ ); (g) AHP466 pretreated ES (adjusted by $\mathrm{KOH}$ ); (h) AHP-pretreated ES (adjusted by $\mathrm{Ca}(\mathrm{OH})_{2}$ ); (i) microwave-pretreated 467 ES; (j) ultrasonic-pretreated ES; (k) Highest cumulative methane yields of different pretreatments for ES.

468 Fig. 3 The CMY during AD process of ES at suitable F/I and OL, (a) NaOH pretreatment; (b) $\mathrm{KOH}$ 469 pretreatment; (c) alkali hydrogen peroxide (AHP) pretreatment (adjusted by $\mathrm{NaOH}$ ); (d) AHP pretreatment 470 (adjusted by $\mathrm{KOH}$ ). 
Figures
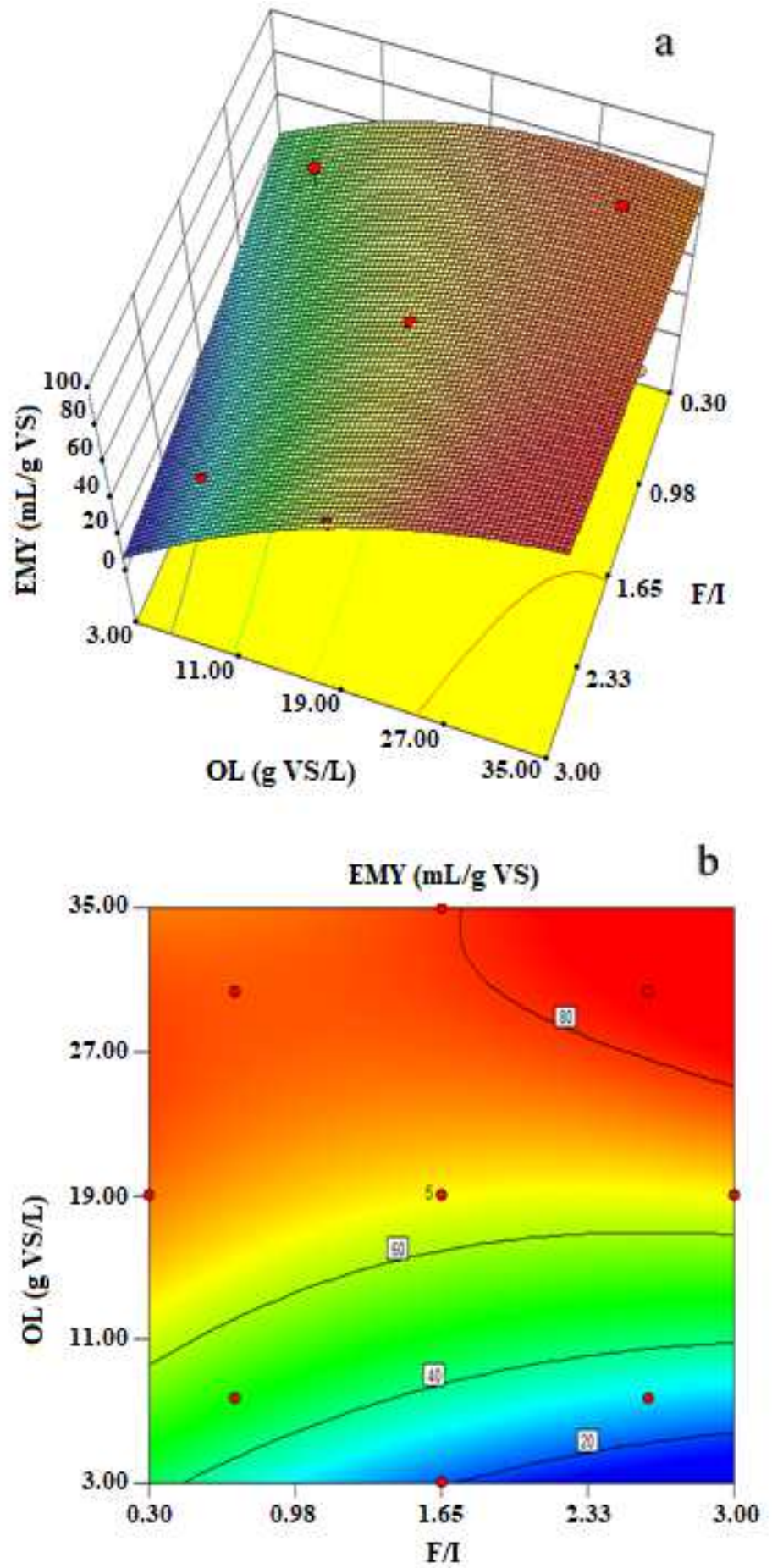

Figure 1

3D response surfaces (a) and 2D contour plots (b) obtained by RSM. 

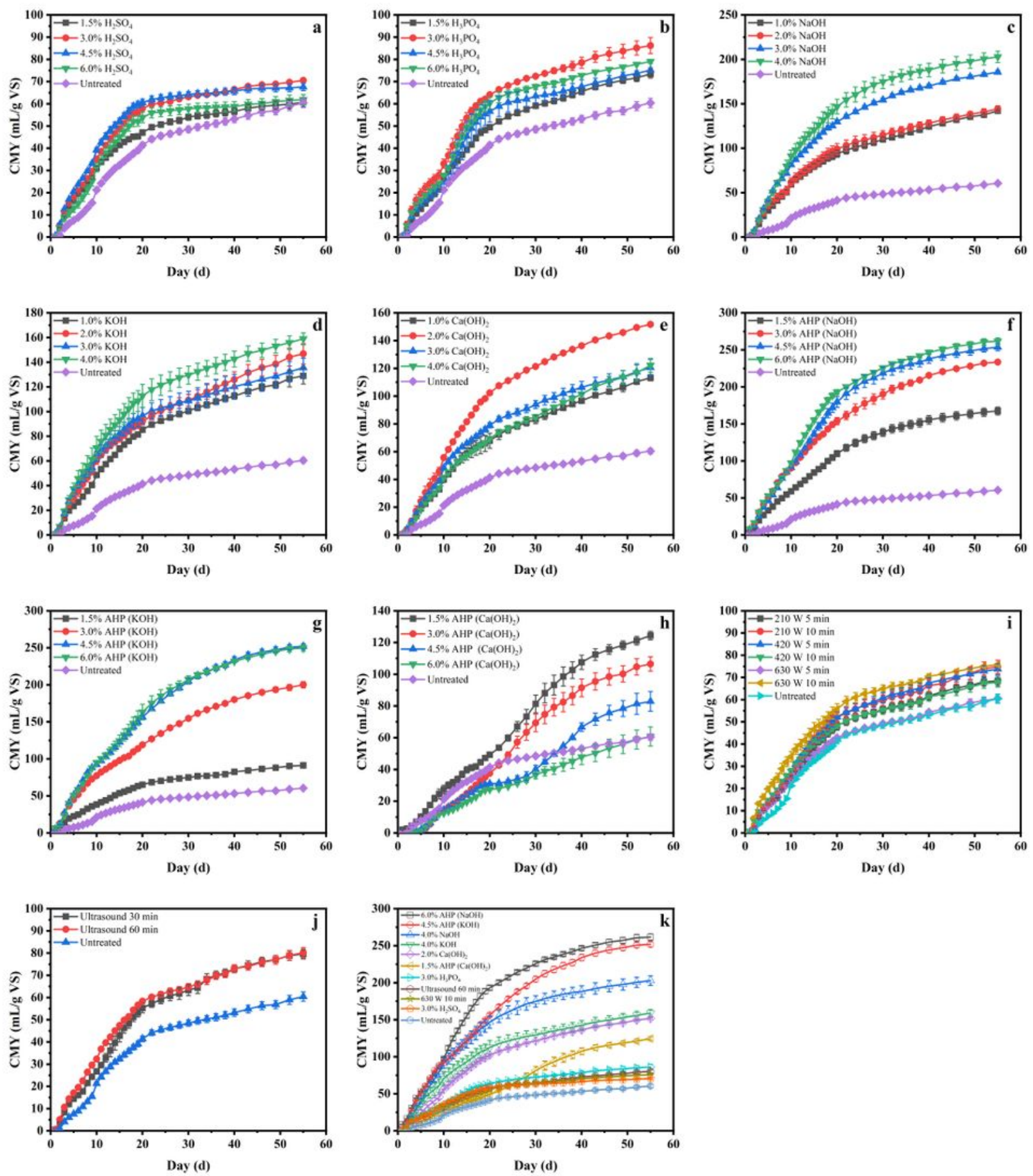

\section{Figure 2}

The CMY of ES, (a) H2SO4-pretreated ES; (b) H3PO4-pretreated ES; (c) NaOH-pretreated ES; (d) $\mathrm{KOH}$ pretreated ES; (e) $\mathrm{Ca}(\mathrm{OH}) 2$-pretreated ES; (f) AHP-pretreated ES (adjusted by $\mathrm{NaOH}$ ); (g) AHP-pretreated ES (adjusted by $\mathrm{KOH}$ ); (h) AHP-pretreated ES (adjusted by $\mathrm{Ca}(\mathrm{OH}) 2$ ); (i) microwave-pretreated ES; (j) ultrasonic-pretreated ES; (k) Highest cumulative methane yields of different pretreatments for ES. 

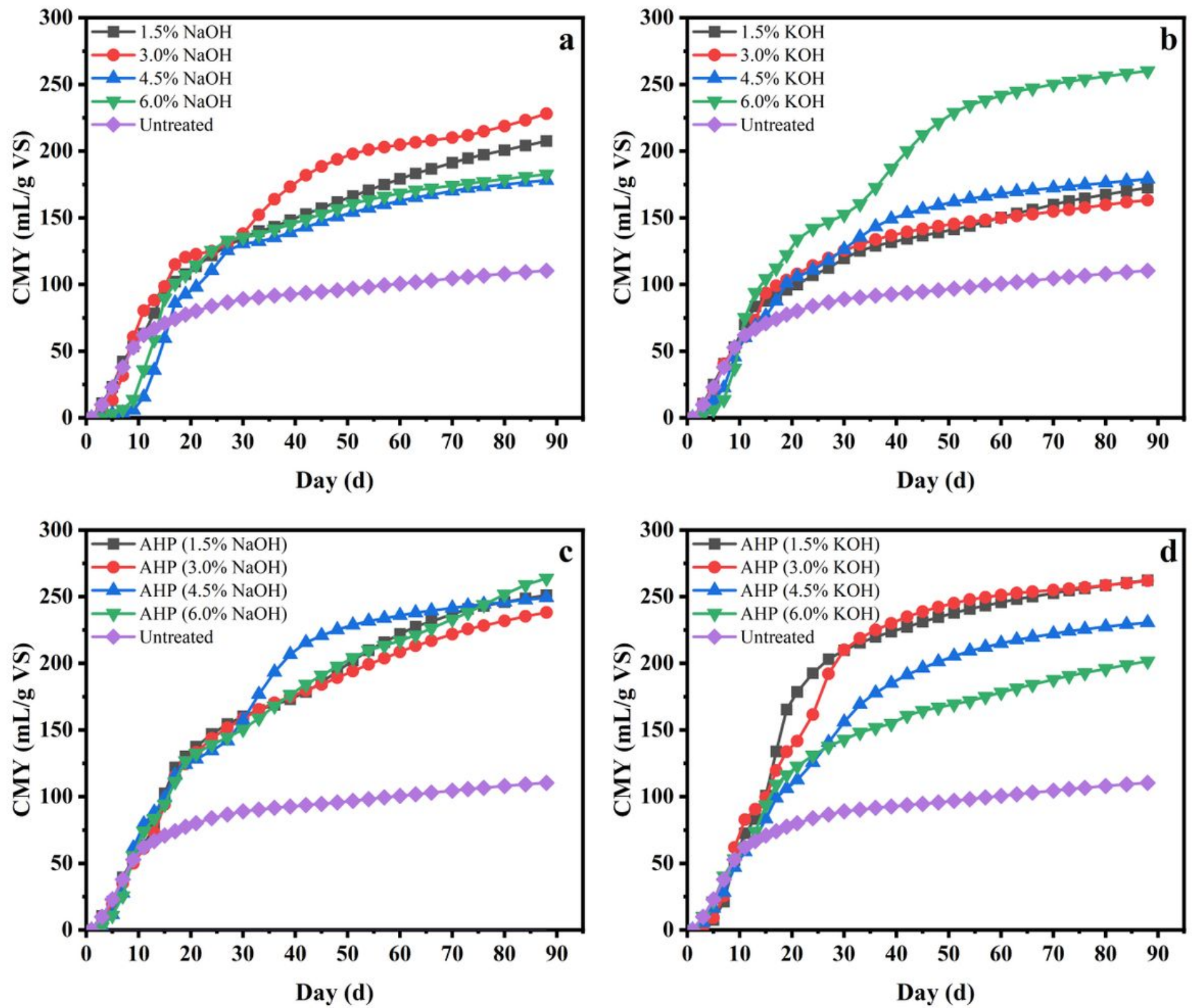

Figure 3

The CMY during AD process of ES at suitable F/I and OL, (a) NaOH pretreatment; (b) KOH pretreatment; (c) alkali hydrogen peroxide (AHP) pretreatment (adjusted by $\mathrm{NaOH}$ ); (d) AHP pretreatment (adjusted by $\mathrm{KOH})$.

\section{Supplementary Files}

This is a list of supplementary files associated with this preprint. Click to download.

- Supplementarymaterials.pdf 